\title{
Greening Drylands with Seawater Easily and Naturally
}

Khaled Moustafa

Editor of ArabiXiv

khaled.moustafa@arabixiv.org

\section{Abstract}

Sun and sea are inexhaustible sources of energy and water that could be used to transform drylands into more viable ecosystems. A sustainable and cost-effective approach is proposed here for greening drylands and restoring wildlife through natural evaporation/condensation cycles using seawater desert-houses (or artificial seawater ponds) that could offer important environmental advantages.

Keywords: alternative farming; artificial seawater pond; desert biodiversity; desert greening; deserthouse dryland house; desert-house; floating farm; movable seawater pond; saline agriculture; seawater desalination; seawater greenhouse; seawater pond; seawater pool; solar desert-houses; seawater desert house.

\section{Introduction}

To maintain viable ecosystems and reduce current and future repercussions of drought and water scarcity, innovative and sustainable farming systems are required. Urban and vertical farming systems are potential solutions that could offer many environmental and agricultural benefits [1]. Other solutions may include developing floating photovoltaic- based agriculture in the sea [2] and breeding new polyploidy crops [3] or land-sea hybrid plant species potentially irrigable with seawater [4] [5]. Sun and seawater surrounding large deserts and drylands in the world offer another important advantage that could be exploited in natural ecological systems to restoring wildlife biodiversity and providing food sources for many native desert fauna and flora species.

\section{Solar desert-houses (or movable seawater ponds)}

In an attempt to greening the desert and revive its dry niches, I propose a simple and costeffective approach that could be developed using artificial and movable solar stills in the form of greenhouses, which we can call as "solar desert-houses" or "artificial seawater ponds" (Fig 1). Based on the same principle as rain formation, these structures could distill seawater naturally and sustainably to provide small, but permanent, amounts of freshwater to satisfy water requirements of many desert species. Large and movable water-tanks or containers 
could thus be manufactured in rectangular or circular forms to be either fixed above the ground or buried in the soil (Fig 1). Seawater could then be supplied into these assemblies and left under natural conditions. As the sun shines most of the time in drylands with average temperatures up to $40-50^{\circ} \mathrm{C}$, seawater will evaporate and condense on the inner side of the roof as freshwater droplets. These droplets could be collected, stored and conducted outside the desert house via small grooves at the bottom-lateral edges, which are connected to perforated hoses or tubes that will deliver the freshwater into the soil (similarly to in-ground irrigation system). As such, a permanent and miniaturized replication of rain system is created naturally with valuable benefits for nomads, plant and animal species in drylands.

\section{Major advantages}

The suggested approach is simple, accessible, cheap and environmentally friendly. Solar desert-houses could be built anywhere in drylands or wastelands, including remote continental arid zones where sun is shining and seawater could be brought through ducts or tubes. Another advantage is that the seawater ponds could be transferred to new locations, removed or stopped at any moment. As the seawater is kept in containers and salts could be recovered from them, there is no soil salinization risk associated with the system. In fact, there would be a double benefit: on one hand, it produces freshwater for desert vegetation and on the other, it produces salts an important byproduct for human consumption or industrial applications. As there is little equipment required for this approach, maintenance operations are easy and minimal, limited to turning the seawater provision system on and off and recovering accumulated salts from the containers. Finally, buried tubes offer an important advantage to minimize the evaporation risk of the freshwater itself by delivering the freshwater droplets directly inside the soil close to the root areas so that plants could benefit from accumulating freshwater droplets more efficiently. However, if freshwater-collecting tubes are designed to be buried, there might be needs for regular controls to make sure that the tube perforations are not blocked by the soil or the tubes should be semi-permeable so that the freshwater water leaks outside by contact with the soil.

\section{Minor disadvantages}

Although the yield of the freshwater produced this way may be low per a unit of time and space, but as the process is sustainable and scalable, the overall volumes of freshwater produced over time could be enough to meet minimal needs of many desert plant species whose needs are basically low. As a result, many desert plant species can prosper and populate the surrounding surfaces around the established seawater ponds to form small oases in the heart of the desert (Fig 1). As the evaporation process is continuous, salts will accumulate in the containers, reducing the volume of evaporable seawater. To prevent this, 
the supply of seawater could be stopped periodically to recover the accumulated salts and allow the system functioning optimally.

While the efficiency in producing freshwater will depend on ambient conditions and materials used in capturing sunlight, the outlined approach could help exploit arable lands more intelligently when it is built at a high density on lands that only need a little freshwater to offer full agricultural potential. Actually, many desert plant species can grow and thrive in extremely dry conditions with only traces of moisture in the soil or in the atmosphere (dew) so that the amount of freshwater produced via the proposed approach could be enough to meet their needs and allow them to grow successfully. Another potential minor hurdle is the risk of evaporation of the produced freshwater itself before it gets absorbed by the soil, particularly if the freshwater droplets are poured on the soil surface but not inside it. To mitigate this hazard, the freshwater-collecting tubes could be half-buried or completely buried in the soil so that the freshwater droplets are injected inside the soil as soon as they are produced. Another potential enhancement is to design the seawater ponds to stock the freshwater produced during the day in lateral reservoirs and to deliver it during the night, when it is cooler, so the evaporation risk is significantly minimized. This could be achieved by using for example light sensors or mechanical adapters that could control the delivery of freshwater only during the dark (i.e., a control by light or optical sensors) or when the accumulated freshwater reaches a certain volume or weight (a mechanical control or a control by weight).

\section{Concluding remarks}

Purifying seawater from its impurities and salts could be attempted naturally in sunny regions using "solar desert-houses" or "artificial seawater ponds" at large scales to produce freshwater for desert vegetation at low cost. The approach is inexpensive and easy to implement to benefit many people and native animal and plant species in large drylands in the world without any particular hurdles. Solar desert-houses could be placed anywhere sun and saltwater are available. By adopting and optimizing such a system, many plant species could grow successfully and provide food sources for desert animals and indirectly for humans. The prospective approach can also contribute to protecting the soil by the growing plants and thus reducing the intensities and frequencies of dust storms in these regions. Developing solar desert-houses would help improve the quality of life for many people and desert species and offer a potentially useful solution for water shortage and desertification effects in large drylands worldwide.

\section{Disclosure: None}




\section{References}

1. Despommier, D., Farming up the city: the rise of urban vertical farms. Trends Biotechnol, 2013. 31(7): p. 388-9.

2. Moustafa, K., Toward Future Photovoltaic-Based Agriculture in Sea. Trends in Biotechnology, 2016. 34(4): p. 257-259.

3. Mason, A.S. and J. Batley, Creating new interspecific hybrid and polyploid crops. Trends Biotechnol, 2015. 33(8): p. 436-41.

4. Moustafa, K., Toward breeding new land-sea plant hybrid species irrigable with seawater for dry regions. Plant Signal Behav, 2015. 10(4): p. e992744.

5. Moustafa, K., Binucleation to breed new plant species adaptable to their environments. Plant Signal Behav, 2015. 10(8): p. e1054586.

\section{Text Box 1: Design specifications for movable seawater ponds.}

The structure of solar desert houses (or movable seawater ponds) could be composed of two main parts (top-right) (Fig 1): a bottom container to be filled with saltwater and an upper curved -light-transparent plastic or Plexiglass roof on which freshwater droplets will condense and trickle down. The structure could be designed to be buried in the soil, as illustrated above, or placed above the ground as a cittern. The dimensions and shapes of the prospective facility could be variable from small to big, and from round to rectangular of, for example, $20 \mathrm{~m}$ length (or diameter if round) by $2 \mathrm{~m}$ width and $2 \mathrm{~m}$ depth (height), or scalable to larger or smaller dimensions to provide the best outcome possible. To increase the longevity of the system and reduce maintenance operations, the materials to be used should be resistant to harsh temperature and salinity conditions (e.g., pottery clay or Plexiglass). The roof's inner condensing layer could be coated with a hydrophobic material to allow the condensed water droplets trickle down as quickly as they are formed to be conducted thru freshwater-collecting tubes directly into the soil. A park of movable stills buried or elevated above the ground could thus be set up at a given density of rows and columns near the coast or far from it. The seawater could be brought to these settings via a pipeline network similarly to oil pipeline frameworks (Fig 1). To avoid any interference with potential infrastructure on land (roads, bridges, fields etc.), the seawater-conducting tubes could be buried in the soil in a similar way to the sewage or urban water network.

As sun is available most of the time in drylands, a programmable water pump functioning on solar energy could be used to pump the saltwater from the sea or ocean. To automatically control the system, sensors could be used to measure the salt and water levels in the containers so that a solar-based water pump could be programmed to pump the seawater when its level in the container is low and stops when it is high. The cycle of seawater provision and evaporation could thus operate indefinitely and naturally as long as sun and saltwater are available. 


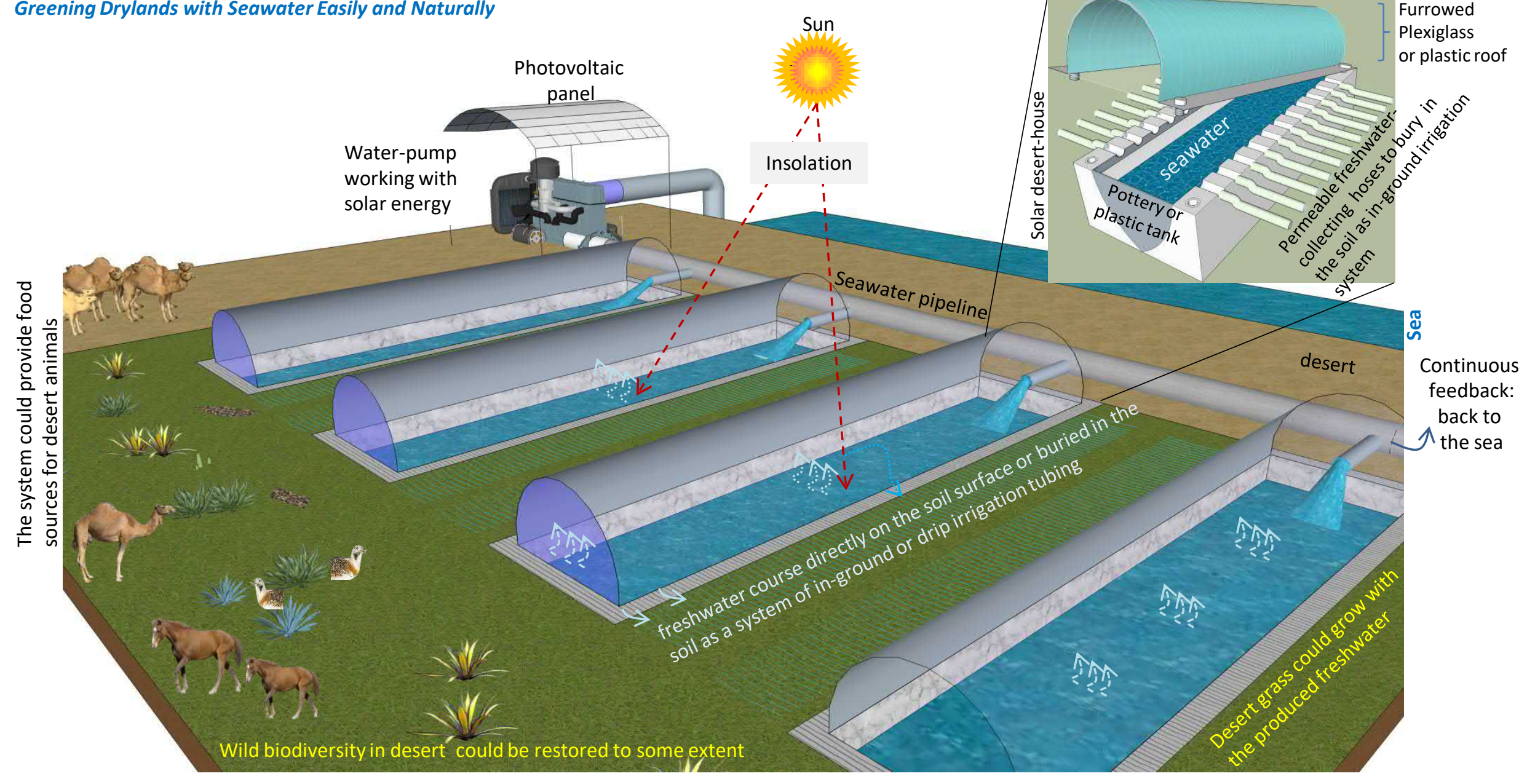

Fig. 1: A streamlined illustration of simple, reusable and cost-effective 'solar desert-houses' (or 'artificial seawater ponds').

In contrast to traditional greenhouses, solar desert-houses are not intended to grow plants inside, but to be filled up with seawater which, under hot dry conditions, will evaporate and condense into freshwater droplets that could satisfy the needs of some plant species growing in the desert (e.g., xerophyte and halophyte species). Artificial seawater ponds would help forming artificial oases in the desert while offering a valuable food source for desert animals such as camels, horses or wild birds etc. When the accumulated salts reach a given threshold at which the evaporation efficiency is reduced, the salts could be recovered by discharging the container from its accumulated salts to be reused again and so on. The desert-houses should be made from materials adapted to harsh climate conditions (i.e., extreme temperatures and high salt concentrations) to minimize maintenance operations. New technologies could help optimizing the proposed system by for example full automation of all the processes, from seawater pumping to salt discharging, though such an automation will increase the overall cost but will improve the system substantially. The excess of seawater brought to the solar houses could be returned back into the sea in a cyclic and sustainable pattern. 